\title{
Structural reevaluation of the electrophilic hypervalent iodine reagent for trifluoromethylthiolation supported by the crystalline sponge method for $\mathrm{X}$-ray analysis
}

\author{
Ekaterina V. Vinogradova, Peter Müller, and Stephen L. Buchwald ${ }^{\star}$ \\ Department of Chemistry, Room 18-490 Massachusetts Institute of Technology Cambridge, MA \\ 02139 (USA)
}

\begin{abstract}
Hypervalent iodine $\lambda^{3}$-benziodoxoles are common electrophilic transfer reagents known for their enhanced stability compared to their non-cyclic analogues. Herein we present data showing that chlorobenziodoxole reacts with two different thiolate nucleophiles (thiocyanate and trifluoromethylthiolate), resulting in the formation of stable thioperoxy complexes rather than the expected benziodoxole derivatives. We further report a revised structure for the earlier described electrophilic trifluoromethylthiolation reagent (1), which was previously believed to contain the benziodoxole framework. Our findings, which are based on a combination of analytical techniques, including the recently introduced crystalline sponge method for X-ray analysis, unambiguously demonstrate that $\mathbf{1}$ is a thioperoxy compound both in solution and the solid state.
\end{abstract}

\section{Keywords}

crystalline sponge crystallography; host-guest systems; hypervalent compounds; thioperoxides; trifluoromethylthiolation

Recently, Shen et al. introduced a new hypervalent iodine reagent for the transfer of an electrophilic trifluoromethylsulfur group (Figure 1, 1). ${ }^{[1]}$ Compound $\mathbf{1}$ was isolated as a colorless liquid and characterized by ${ }^{1} \mathrm{H},{ }^{13} \mathrm{C}$, and ${ }^{19} \mathrm{~F}$ NMR spectroscopy, as well as elemental analysis. Based on these data, Shen proposed that $\mathbf{1}$ contains the sulfur-bound hypervalent iodine motif, similar to all previously reported benziodoxole and benziodoxolone transfer reagents (Figure 1). ${ }^{[2-9]}$

As part of our work on the synthesis of aryl isocyanates, ${ }^{[10]}$ we were interested in developing new reagents based on the benziodoxole motif for isocyanate and isothiocyanate group transfer chemistry. We anticipated that the ambidentate cyanate and thiocyanate nucleophiles could potentially react with reagent 3 at either the nitrogen or group 16 element (oxygen or sulfur) nucleophilic sites. Indeed, when $\mathbf{3}$ was treated with silver cyanate, a mixure of isomeric 1-cyanatobenziodoxoles was obtained, with the major product arising from reaction at the nitrogen atom $(\mathbf{4}$, Scheme 1a). In contrast, the reaction of $\mathbf{3}$ with silver thiocyanate yielded a single compound that did not contain the expected benziodoxole

*sbuchwal@mit.edu. 
scaffold (5, Scheme 1b). As shown in Scheme 1, the single crystal X-ray analysis of compound $\mathbf{5}$ revealed that the thiocyanate-group was S-bound to the oxygen atom of $\mathbf{2}$ rather than to the iodine. ${ }^{[11,12]}$

Intrigued by this result, we conducted a brief comparison of the ${ }^{1} \mathrm{H}$ NMR spectra of the benziodoxoles and 2- iodobenzyl alcohol-derivatives that are shown in Figure 2. We found that the two compound classes (closed benziodoxole vs. open benzyl alcohol) generally display different characteristic signals in the aromatic region. Most notably, the aromatic protons that are para to the alkyl group $\left(\mathrm{H}_{\mathrm{b}}\right)$ exhibited significant $(0.5 \mathrm{ppm}$ or greater) downfield shifts in the closed compounds (Figure 2a,b) when compared to the open ones (Figure 2c,d). As described above, the sulfur-based nucleophile afforded the corresponding open compound (Figure 2d) with complete selectivity, which is in contrast to the reported benziodoxole structure of the related trifluoromethylthiolation reagent $\mathbf{1}$. Compound $\mathbf{1}$ was synthesized according to literature procedure ${ }^{[1 \mathrm{a}]}$ and exhibited identical spectral properties as reported. To our surprise, the ${ }^{1} \mathrm{H}$ NMR spectrum of $\mathbf{1}$ (Figure 2e) resembles those of the open-form compounds more closely than the spectra of the closed-form ones, suggesting that 1 could potentially exist as the open thioperoxy compound rather than the benziodoxole. The oxidation state of iodine in $\mathbf{1 , 5}$ and $\mathbf{6}$ as $\mathrm{I}^{\mathrm{I}}$ in solution was further corroborated by ${ }^{13} \mathrm{C}$ NMR spectroscopy, as outlined previously by Katritzky et al. ${ }^{[13]}$

To further evaluate the structure of the Shen reagent, we undertook two parallel studies that would allow us to obtain X-ray crystallographic structural data. ${ }^{[14,15]}$ We first sought to prepare a solid analogue of the trifluoromethylthio-transfer reagent. According to the route outlined in Scheme 2, we were able to construct a modified reagent 6 that contained the dichlorotrimethoxyphenyl substituent at $\mathrm{C} 4$ of the phenyl ring. This new reagent displayed the characteristic aromatic ${ }^{1} \mathrm{H}$ NMR signal that indicated a compound that did not contain the benziodoxole scaffold (Figure 2f). X-ray diffraction analysis of single crystals of $\mathbf{6}$ provided unequivocal structural evidence that the $\mathrm{SCF}_{3}$ group is bound to oxygen rather than to iodine (Scheme 2).

To evaluate the potential steric and electronic effects that installation of the functionalized aromatic substituent could impart to the reagent, we compared the reactivity of $\mathbf{6}$ and $\mathbf{1}$ in previously reported $\mathrm{SCF}_{3}$-transfer reactions. Under the optimized conditions reported by Shen et al. for $\beta$-ketoester- (Scheme 3a) or Cu-catalyzed arylboronic acidtrifluoromethylthiolation (Scheme 3b), ${ }^{[1 \mathrm{a}]}$ the two reagents displayed nearly identical reactivity profiles (Scheme 3 ).

Although it is possible that there exists a Curtin-Hammet scenario where both forms of the reagent exist in equilibrium in solution and the reactivity arises from the hypervalent iodine structure, no evidence for such an equilibrium was observed by ${ }^{1} \mathrm{H}$ or ${ }^{19} \mathrm{~F}$ NMR spectroscopy, even at low temperatures $\left(-80^{\circ} \mathrm{C}\right)$. Furthermore, the similarity of the thioperoxide structure to the previously reported nitrogen-based electrophilic trifluoromethylthiolation reagents by the groups of Billard ${ }^{[16]}$ and Rueping ${ }^{[17]}$ (Scheme 4a and $\mathrm{b}$ ), as well as the disulfide reagents used for directed $\mathrm{Cu}$-promoted sulfenylation of $\mathrm{sp}^{2}$ $\mathrm{C}-\mathrm{H}$ bonds by Daugulis et al. ${ }^{[18]}$ (Scheme 4c) supports the hypothesis that the observed reactivity ${ }^{[1 \mathrm{a}, \mathrm{c}]}$ could arise from the thioperoxide fragment itself. 
Fujita recently introduced a new method for the structure determination of liquid compounds trapped in the pores of a host Metal Organic Framework (MOF). ${ }^{[19]}$ We were interested in applying this methodology to gain access to the X-ray structure of the parent reagent $\mathbf{1}$. The MOF material was prepared by slow diffusion of the solution of $\mathrm{ZnI}_{2}$ in methanol into the solution of 2,4,6-Tri(4-pyridyl)-1,3,5-triazine in a mixture of nitrobenzene and methanol. Soaking the resulting crystals in cyclohexane at $50{ }^{\circ} \mathrm{C}$ for 2 weeks (used solvent was replaced by fresh solvent each day) allowed for the majority of nitrobenzene in the pores of the MOF to be exchanged with more labile cyclohexane molecules. ${ }^{[20]}$ A consecutive soak of the crystals in the analyte provided X-ray quality crystals of the host-guest complex $1 @$ MOF. Subsequent structure determination using a variety of advanced refinement techniques $^{[21]}$ revealed the presence of $92 \%$ of reagent 1 per asymmetric unit of the crystal structure of $1 @ \mathrm{MOF}$, disordered over three crystallographically independent sites (see Supporting Information for details). As shown in Scheme 5, the crystallographically-derived structure of $\mathbf{1}$ does not contain the benziodoxole fragment, and the $\mathrm{SCF}_{3}$-group is bound to the oxygen atom.

In summary, we have discovered that the reaction of chlorobenziodoxole with two sulfurcontaining nucleophiles leads to the formation of rearranged products containing stable thioperoxy groups. A combination of spectroscopic techniques, derivatization experiments and the crystalline sponge method recently introduced by Fujita, ${ }^{[19]}$ allowed for unambiguous confirmation of the open form thioperoxide structure of the recently reported trifluoromethylthiolation reagent $\mathbf{1}$ both in solution and in solid state at room temperature. Importantly, while these results do not affect the chemical reactivity studies utilizing reagent $\mathbf{1}$ as recently reported by Shen, ${ }^{[1 \mathrm{a}]}$ they do suggest that other mechanistic pathways for electrophilic trifluoromethylthiolation are possible. ${ }^{[1 c]}$

\section{Supplementary Material}

Refer to Web version on PubMed Central for supplementary material.

\section{Acknowledgments}

Research reported in this publication was supported by the National Institute of Health under award number GM58160. The departmental X-ray diffraction instrumentation was purchased with the help of funding from the National Science Foundation (CHE-0946721). We are grateful to Dr. Stacey J. Smith for help in obtaining crystal structures of compounds 4 and 5. We thank Dr. Alex M. Spokoyny and Dr. Katrin Niedermann for helpful discussions, and Dr. Alex M. Spokoyny, Dr. Sean M. Smith and Dr. Nathan T. Jui for help with preparing this manuscript. We would also like to acknowledge a reviewer for drawing our attention to reference [13] and the use of ${ }^{13} \mathrm{C}$ NMR spectroscopy as a diagnostic tool for the structural elucidation of $\mathbf{1}$. The content is solely the responsibility of the authors and does not necessarily represent the official views of the National Institutes of Health.

\section{References}

[1] a). Shao X, Wang X, Yang T, Lu L, Shen Q. Angew. Chem. 2013; 125:3541-3544.Angew. Chem. Int. Ed. 2013; 52:3457-3460.b) Ritter SK. C\&EN. 2013; 91:32-33.c) Wang X, Yang T, Cheng X, Shen Q. Angew. Chem. 2013; 125:13098-13102.Angew. Chem. Int. Ed. 2013; 52:1286012864.d) Deng Q-H, Rettenmeier C, Wadepohl H, Gade LH. Chem. Eur. J. 2013; 20:93-97. [PubMed: 24339164] 
[2] a). Reviews on benziodoxole and benziodoxolone reagents: Zhdankin VV. Curr. Org. Synth. 2005; 2:121-145. Brand JP, González DF, Nicolai S, Waser J. Chem. Commun. 2011; 47:102-115.

[3] a). Benziodoxole and benziodoxolone reagents gained particular attention from the research community due to their enhanced stability compared to their non-cyclic hypervalent iodine analogues: Ochiai M, Ito T, Masaki Y, Shiro M. J. Am. Chem. Soc. 1992; 114:6269-6270. Ochiai M, Sueda T, Miyamoto K, Kiprof P, Zhdankin VV. Angew. Chem. 2006; 118:8383-8386. Angew. Chem. Int. Ed. 2006; 45:8203-8206.

[4] a). For hypervalent iodine trifluoromethyl group transfer reagents, see: Eisenberg P, Gischig S, Togni A. Chem. Eur. J. 2006; 12:2579-2586. [PubMed: 16402401] Kieltsch I, Eisenberg P, Stanek K, Togni A. Chimia. 2008; 62:260-263. Niedermann K, Früh N, Vinogradova E, Wiehn MS, Moreno A, Togni A. Angew. Chem. 2011; 123:1091-1095. Angew. Chem. Int. Ed. 2011; 50:1059-1063. Deng Q-H, Wadepohl H, Gade LH. J. Am. Chem. Soc. 2012; 134:10769-10772. [PubMed: 22693950] Liu X, Wu X. Synlett. 2013; 24:1882-1886. and references therein.

[5]. For hypervalent iodine cyano group transfer reagents, see: Zhdankin VV, Kuehl CJ, Krasutsky AP, Bolz JT, Mismash B, Woodward JK, Simonsen AJ. Tetrahedron Lett. 1995; 36:7975-7978.

[6] a). For hypervalent iodine alkynyl group transfer reagents, see: Brand JP, Charpentier J, Waser J. Angew. Chem. 2009; 121:9510-9513. Angew. Chem. Int. Ed. 2009; 48:9346-9349. Brand JP, Waser J. Angew. Chem. 2010; 122:7462-7465. Angew. Chem. Int. Ed. 2010; 49:7304-7307. Brand JP, Chevalley C, Scopelliti R, Waser J. Chem. Eur. J. 2012; 18:5655-5666. [PubMed: 22438043] Frei R, Waser J. J. Am. Chem. Soc. 2013; 135:9620-9623. [PubMed: 23777551] Li Y, Brand JP, Waser J. Angew. Chem. 2013; 125:6875-6879. Angew. Chem. Int. Ed. 2013; 52:6743-6747. González DF, Brand JP, Mondière R, Waser J. Adv. Synth. Catal. 2013; 355:1631-1639.

[7]. For hypervalent iodine fluorine atom transfer reagents, see: Geary GC, Hope EG, Singh K, Stuart AM. Chem. Commun. 2013; 49:9263-9265.

[8]. For hypervalent iodine difluoromethyl group transfer reagents, see: He Z, Luo T, Hu M, Cao Y, Hu J. Angew. Chem. 2012; 124:4010-4013. Angew. Chem. Int. Ed. 2012; 51:3944-3947.

[9] a). For hypervalent iodine azide transfer reagents, see: Zhdankin VV, Krasutsky AP, Kuehl CJ, Simonsen AJ, Woodward JK, Mismash B, Bolz JT. J. Am. Chem. Soc. 1996; 118:5192-5197. Vita MV, Waser J. Org. Lett. 2013; 15:3246-3249. [PubMed: 23773166]

[10] a). Vinogradova EV, Fors BP, Buchwald SL. J. Am. Chem. Soc. 2012; 134:11132-11135. [PubMed: 22716197] b) Vinogradova EV, Park NH, Fors BP, Buchwald SL. Org. Lett. 2013; 15:1394-1397. [PubMed: 23441814]

[11]. Although an exact mechanism for the formation of thioperoxide species is not known, a plausible mechanism involves reductive elimination from the intermediate hypervalent iodine species facilitated by the strongly electron-withdrawing substituent on the sulfur. Similar reactivity has been observed in reactions with Togni reagents, where unreactive trifluoromethyl ethers and esters were obtained as byproducts in the trifluoromethylations: Niedermann K, Früh N, Senn R, Czarniecki B, Verel R, Togni A. Angew. Chem. 2012; 124:6617-6621. Angew. Chem. Int. Ed. 2012; 51:6511-6515. This process has been shown to be accelerated by strongly Lewis and Brønsted acidic catalysts in the case of benziodoxolone reagents: Fantasia S, Welch JM, Togni A. J. Org. Chem. 2009; 75:1779-1782. [PubMed: 20121229]

[12]. CCDC 978927 (4), 978928 (5), 978929 (6), and 978984 (1@MOF) contain the supplementary crystallographic data for this paper. These data can be obtained free of charge from The Cambridge Crystallographic Data Centre via www.ccdc.cam.ac.uk/data_request/cif.

[13]. Katritzky AR, Gallos JK, Durst HD. Magn. Reson. Chem. 1989; 27:815-822.

[14]. For select X-ray structures of benziodoxole reagents, see: Ref. [4a], [9a], and Legault CY, Prévost J. Acta Cryst. 2012; E68:o1238. Zhdankin VV, Kuehl CJ, Arif AM, Stang PJ. Mendeleev Commun. 1996; 6:50-51.

[15] a). Other existing analytical methods for determination of benziodoxole structures include iodine Mössbauer spectroscopy: Ehrlich BS, Kaplan M. J. Chem. Phys. 1971; 54:612-620. and IR of the carbonyl group for benziodoxolone reagents: Zhdankin VV, McSherry M, Mismash B, Bolz JT, Woodward JK, Arbit RM, Erickson S. Tetrahedon Lett. 1997; 38:21-24. Panetta CA, Garlick SM, Durst HD, Longo FR, Ward JR. J. Org. Chem. 1990; 55:5202-5205. 
[16] a). Baert F, Colomb J, Billard T. Angew. Chem. 2012; 124:10528-10531.Angew. Chem. Int. Ed. 2012; 51:10382-10385.b) Alazet S, Zimmer L, Billard T. Angew. Chem. 2013; 125:1101411017.Angew. Chem. Int. Ed. 2013; 52:10814-10817.

[17]. Bootwicha T, Liu X, Pluta R, Atodiresei I, Rueping M. Angew. Chem. 2013; 125:1309313097.Angew. Chem. Int. Ed. 2013; 52:12856-12859.

[18]. Tran LD, Popov I, Daugulis O. J. Am. Chem. Soc. 2012; 134:18237-18240. [PubMed: 23102009]

[19]. Inokuma Y, Yoshioka S, Ariyoshi J, Arai T, Hitora Y, Takada K, Matsunaga S, Rissanen K, Fujita M. Nature. 2013; 495:461-466. [PubMed: 23538828]

[20]. Inokuma Y, Yoshioka S, Ariyoshi J, Arai T, Fujita M. Nat. Protoc. 2014; 9:246-252. [PubMed: 24407353]

[21]. Müller P. Crystallography Reviews. 2009; 15:57-83. 

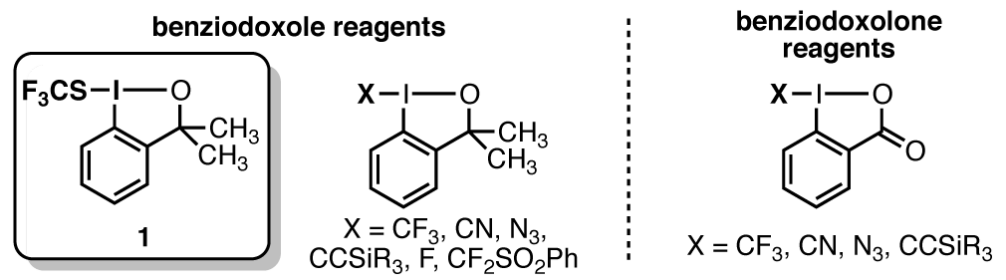

Figure 1.

The reported structure of the reagent for electrophilic trifluoromethylthiolation (1) recently introduced by Shen et al., and representative examples of other reported benziodoxole-based hypervalent iodine transfer reagents. 


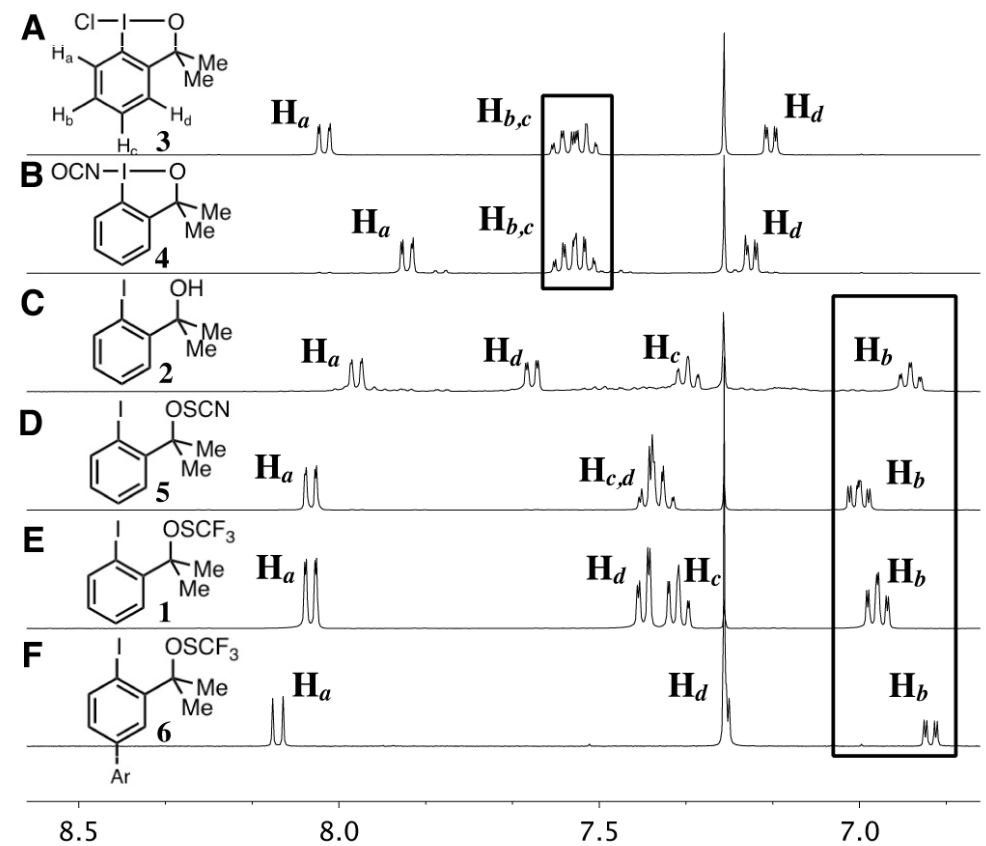

Figure 2.

Comparison of the aromatic region of the ${ }^{1} \mathrm{H}$ NMR spectra of hypervalent-iodine based transfer reagents and novel thioperoxide reagents. 


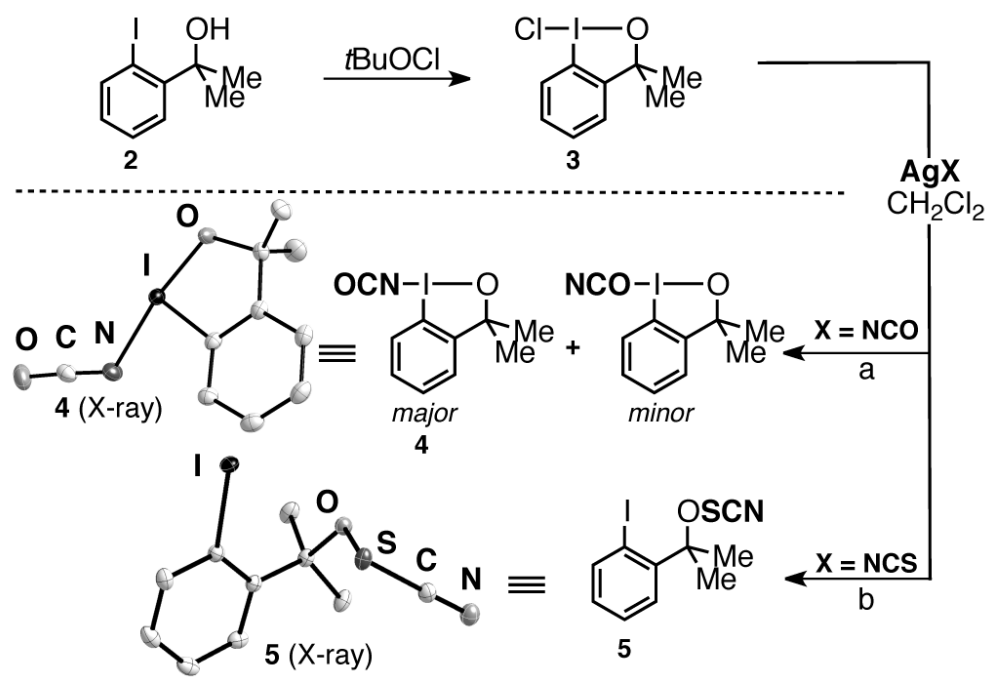

Scheme 1.

Synthesis of novel electrophilic transfer reagents and crystal structures of reagents $\mathbf{4}$ and $\mathbf{5}$. Thermal ellipsoid plots are drawn at $50 \%$ probability, hydrogen atoms are omitted for clarity. 

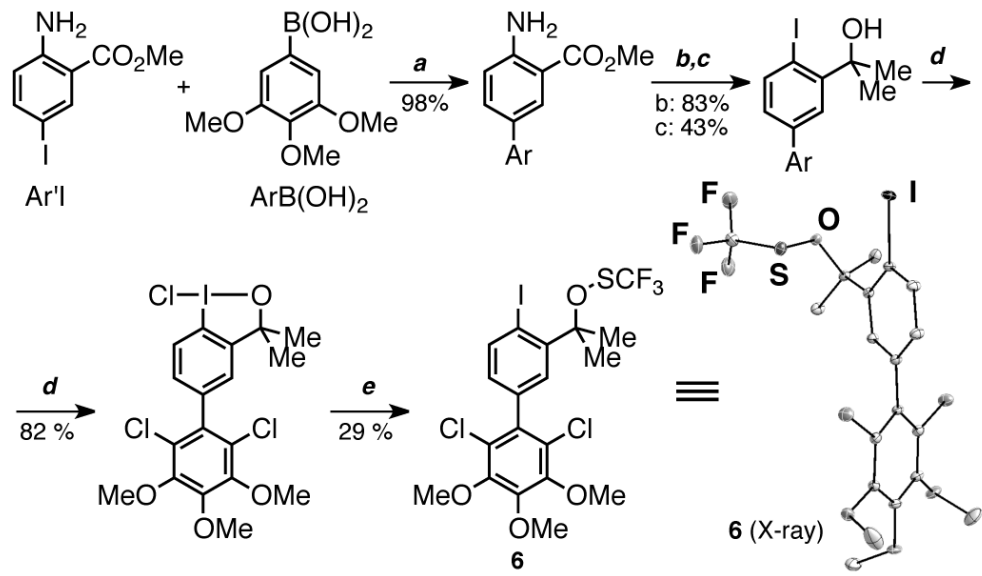

\section{Scheme 2.}

Synthesis of a solid trifluoromethylthiolation reagent and the crystal structure of reagent $\mathbf{6}$. Thermal ellipsoid plot is drawn at $50 \%$ probability, hydrogen atoms are omitted for clarity. Reaction conditions: a. Ar'I (1 equiv), $\mathrm{ArB}(\mathrm{OH})_{2}$ (1.5 equiv), $\mathrm{Pd}(\mathrm{OAc})_{2}(2 \mathrm{~mol} \%)$, SPhos (4 mol\%), $\mathrm{K}_{3} \mathrm{PO}_{4}$ (2 equiv), toluene, $110{ }^{\circ} \mathrm{C}, 18 \mathrm{~h}$; b. $p$ - $\mathrm{TsOH}$ ( 3 equiv), $\mathrm{CH}_{3} \mathrm{CN}$, then $\mathrm{KI}(2.5$ equiv), $\mathrm{NaNO}_{2}$ (2 equiv), $\mathrm{H}_{2} \mathrm{O}, 5 \mathrm{~h}$; c. $\mathrm{MeMgBr}$ ( 4 equiv), $\mathrm{Et}_{2} \mathrm{O}, 40{ }^{\circ} \mathrm{C}, 5 \mathrm{~h}$; d. $t \mathrm{BuOCl}(4$ equiv), THF/CH${ }_{2} \mathrm{Cl}_{2}(2: 1), 2$ h; e. $\mathrm{AgSCF}_{3}$ (1 equiv), THF, $50{ }^{\circ} \mathrm{C}, 1$ h. $p \mathrm{TsOH}=$ paratoluenesulfonic acid, SPhos=2-dicyclohexylphosphino-2',6'-dimethoxy-1,1'-biphenyl. 
a)

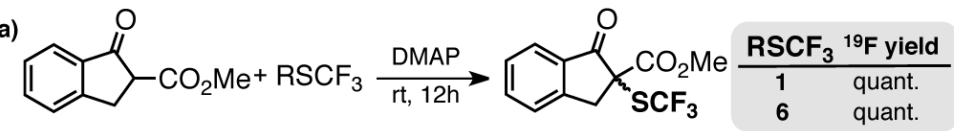

b)

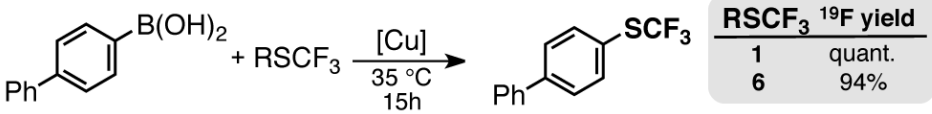

Scheme 3.

Representative reactions of reagents $\mathbf{1}$ and $\mathbf{6}$ with $\beta$-ketoesters (a) and arylboronic acids (b). For detailed reaction conditions, see: Ref. [1a] and Supporting Information. DMAP = N,Ndimethylaminopyridine. 
a)

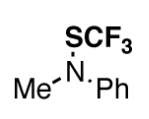

b)

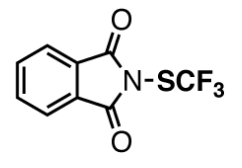

c)

RS. $\mathrm{SR} \quad \mathrm{R}=\mathrm{CF}_{3}, \mathrm{Alk}, \mathrm{Ar}$

Scheme 4.

Trifluoromethylthiolation reagents reported by Billard (a), Rueping (b), and Daugulis (c). 


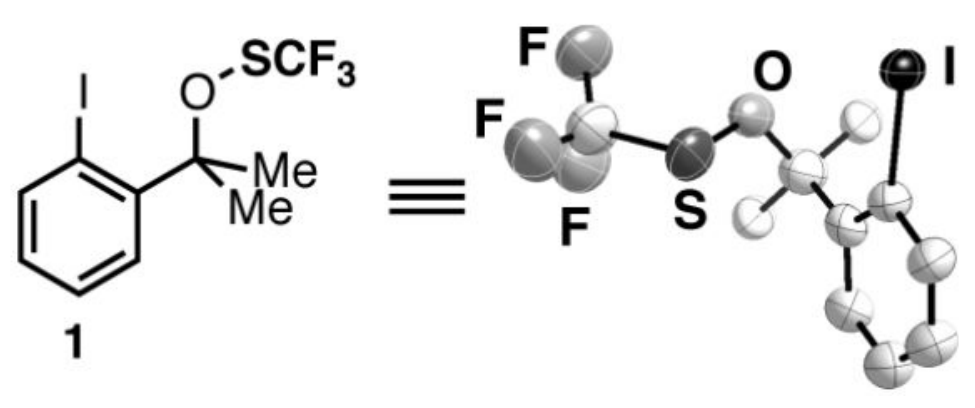

Scheme 5.

Crystal structure of the guest molecule $\mathbf{1}$ observed in the cavities of the MOF. Thermal ellipsoid plot is drawn at 50\% probability, hydrogen atoms are omitted for clarity. 